Pharmaceuticals Corporation, Esther Yi Employee of: Novartis Pharmaceuticals Corporation

DOI: 10.1136/annrheumdis-2020-eular.506

Figure 2. (A) Prior Medication Use, (B) Number of Prior Biologics Used, and (C) Reasons for Discontinuation of Previous Biologic* Among Patients With AS at the Index Date
A

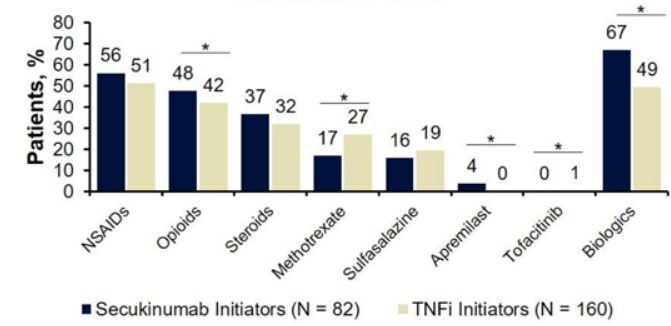

B

$\begin{array}{cc}\begin{array}{l}\text { No. of Prior Biologics Among Biologic- } \\ \text { Experienced Secukinumab Initiators ( } \mathrm{N}=55 \text { ) }\end{array} & \begin{array}{c}\text { No. of Prior Biologics Among Biologic- } \\ \text { Experienced TNFi Initiators ( }=79)\end{array}\end{array}$

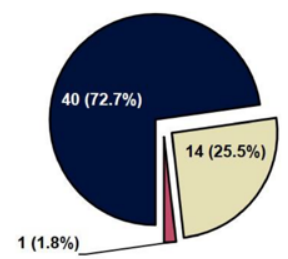

-Exactly 1 aExactly $2 \quad \square \geq 3$

C Reasons for Discontinuation of Previous

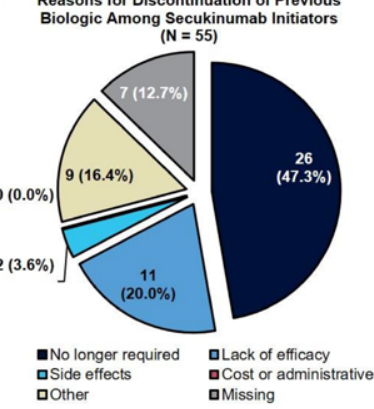

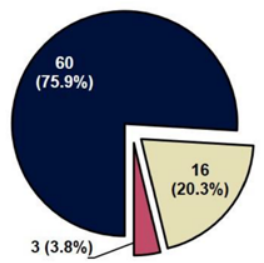

-Exactly 1 aExactly $2 \quad \square \geq 3$

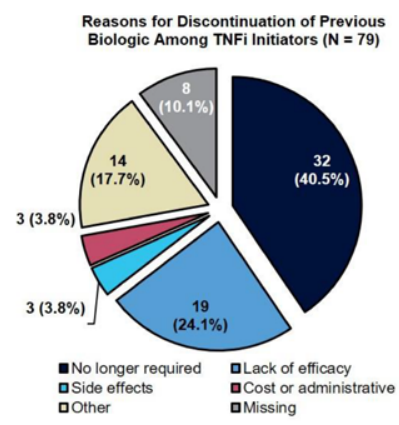

SMD, standardized mean difference.

- Comparisons with SMD $>0.1$ were suggestive of clinically relevant differences.

\section{FRI0270 ONE-YEAR EFFECTIVENESS, RETENTION RATE AND SAFETY OF SECUKINUMAB IN ANKYLOSING SPONDYLITIS AND PSORIATIC ARTHRITIS: A REAL- LIFE MULTICENTRE STUDY}

M. S. Chimenti ${ }^{1}$, G. L. Fonti ${ }^{1}$, P. Conigliaro ${ }^{1}$, F. Sunzini ${ }^{1}$, R. Scrivo ${ }^{2}$, L. Navarini ${ }^{3}$, P. Triggianese ${ }^{1}$, G. Peluso ${ }^{4}$, P. Scolieri ${ }^{5}$, R. Caccavale ${ }^{6}$, A. Picchianti-Diamanti $^{7}$, E. De Martino ${ }^{1}$, S. Salemi ${ }^{7}$, D. Birra ${ }^{4}$, A. Altobelli ${ }^{2}$, M. Paroli ${ }^{6}$, V. Bruzzese ${ }^{5}$, B. Laganà ${ }^{7}$, E. Gremese ${ }^{4}$, F. Conti ${ }^{2}$, A. Afeltra ${ }^{3}$, R. Perricone ${ }^{1} .{ }^{1}$ Rheumatology, Allergology and Clinical Immunology, University of Rome Tor Vergata, Rome, Italy; ${ }^{2}$ Reumatologia, Dipartimento di Medicina Interna e Specialità Mediche, Sapienza Università di Roma, Rome, Italy; ${ }^{3}$ Unit of Allergology, Immunology and Rheumatology, Department of Medicine, Università Campus Bio-Medico di Roma, Rome, Italy; ${ }^{4}$ stituto di Reumatologia e Scienze Affini Università Cattolica del Sacro Cuore- Fondazione Policlinico Universitario Agostino Gemelli - IRCCS- Presidio Columbus, Rome, Italy; ${ }^{5}$ UOC di Medicina interna e Reumatologia, Ospedale Nuovo Regina Margherita, Rome, Italy; ${ }^{6}$ Dipartimento di Scienze e Biotecnologie Medico-chirurgiche, Sapienza Università di Roma, Polo Pontino, Latina, Italy; ${ }^{7}$ Department of Clinical and Molecular Medicine, Sant'Andrea University Hospital, Sapienza University of Rome, Rome, Italy

Background: Secukinumab (SEC) is the first interleukin-17A inhibitor showing efficacy in both ankylosing spondylitis (AS) and psoriatic arthritis (PsA) in randomised trials, but real-life data are lacking.

Objectives: In this prospective observational study, we evaluated the effectiveness and safety of SEC in patients with AS and PSA in a real-life setting.
Methods: From September 2018 to September 2019, data were collected from 168 consecutive outpatients at baseline (T0) and at 6 (T6) and 12 months (T12) after starting SEC (39 AS, 23\%; 129 PsA, $77 \%$ ).

Results: Significant improvement was seen at T6 and T12 for all clinical variables, including TJC, SJC, ESR, CRP, DAPSA, ASDAS-CRP, and BASDAI, as well as in patient-reported outcomes such as VAS-pain. By multivariable regression analysis, in AS patients high BASDAl at T0 correlated with diagnostic delay $\left(R^{2}=0.4 ; p=0.009\right)$ and peripheral joint involvement $\left(R^{2}=0.4 ; p=0.04\right)$. During follow-up, reduction of BASDAI positively correlated with high ESR $\left(R^{2}=0.65\right.$; $\mathrm{p}=0.04)$. ASDAS-CRP at TO positively correlated with high ESR $\left(R^{2}=0.34\right.$ $\mathrm{p}=0.004)$. Reduction of ASDAS-CRP from T0 to T6 correlated with current smoking status $\left(R^{2}=0.42 ; p=0.0005\right)$. In PsA patients, reduction of DAPSA score from T0 to T12 negatively correlated with the presence of metabolic syndrome $\left(R^{2}=0.41 ; p=0.0025\right)$. Retention rate showed good drug survival and an influence of female sex (Figure 1) in the survival curve in only AS patients, but no differences based on BMI, gender and lines of treatment were observed (Figure 2). SEC was well tolerated: Eleven patients discontinued treatment for non-severe adverse events Conclusion: We demonstrated the effectiveness and safety of SEC in patients with AS and PsA in a real-life setting for the first time. No gender differences were observed; however, less clinical improvement was seen in smokers and in patients with metabolic syndrome

References: No references.

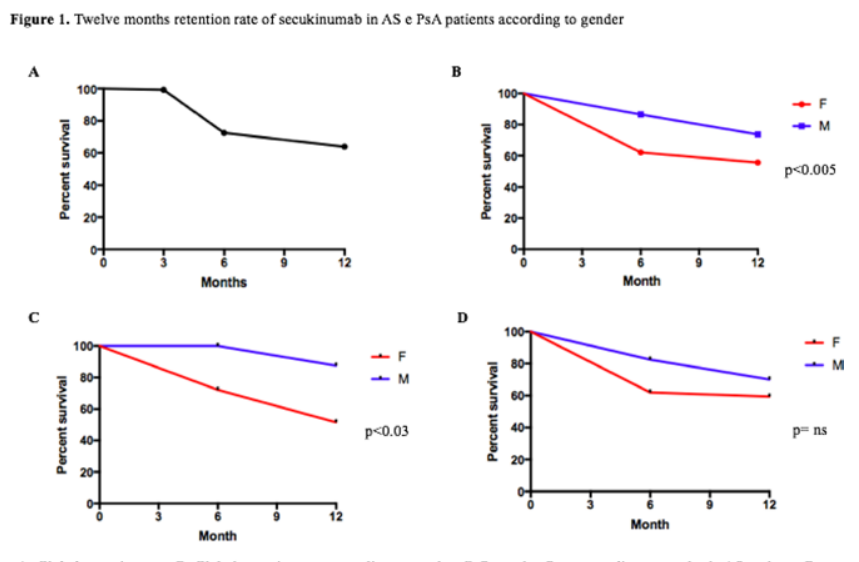

A. Global retention rate; B. Global retention rate according to gender; C. Retention Rate according to gender in AS patients; D. Retention Rate according to gender in PsA patients
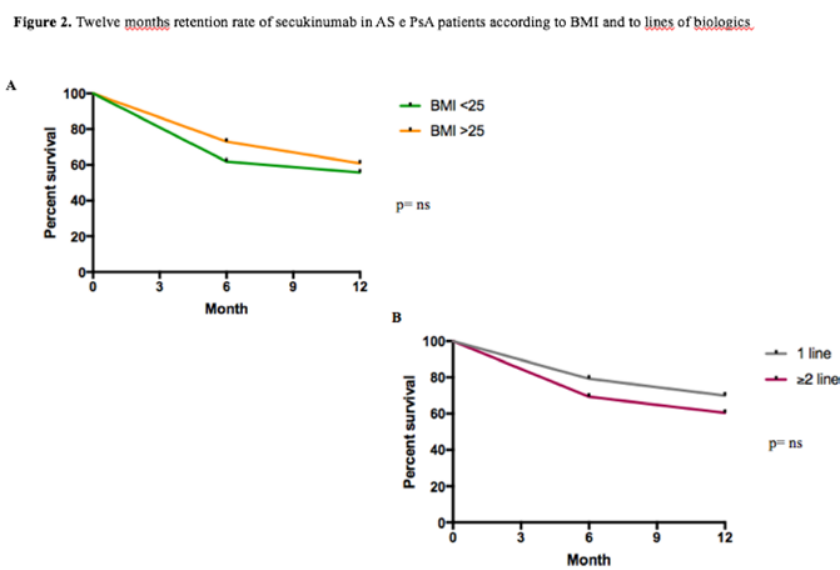

A. Retention Rate according to BMI; B. Retention Rate aceording to lines of biologits

Disclosure of Interests: Maria Sole Chimenti: None declared, giulia lavinia fonti: None declared, Paola Conigliaro: None declared, flavia sunzini: None declared, Rossana Scrivo: None declared, luca navarini: None declared, paola triggianese: None declared, giusy peluso: None declared, Palma Scolieri: None declared, rosalba caccavale: None declared, Andrea Picchianti-Diamanti: None declared erica de martino: None declared, simonetta salemi: None declared, domenico birra: None declared, Alessio Altobelli: None declared, marino paroli: None declared, Vincenzo Bruzzese: None declared, Bruno Laganà: None declared Elisa Gremese Speakers bureau: Abbvie, BMS, Celgene, Jannsen, Lilly, MSD, Novartis, Pfizer, Sandoz, UCB, fabrizio conti Speakers bureau: BMS, Lilly, Abbvie, Pfizer, Sanofi, Antonella Afeltra: None declared, Roberto Perricone: None declared DOI: 10.1136/annrheumdis-2020-eular.3777 